\title{
Middle Colic Artery
}

National Cancer Institute

\section{Source}

National Cancer Institute. Middle Colic Artery. NCI Thesaurus. Code C52981.

An artery arising from the superior mesenteric artery that supplies the transverse colon. 